Book Review

\title{
Ferriols, Roque, Sulyap sa Aking Pinanggalingan, ed. by Leovino Ma. Garcia ${ }^{1}$
}

Jovito V. Cariño

$\mathrm{K}$ ilala si Roque Ferriols bilang isa sa mga pasimuno ng ibayong pagpapasigla ng interes sa pamimilosopiyang Filipino. Sa loob ng nemit illan lamang talaga kahulugan na ng salitang "meron" ngunit iilan lamang talaga ang nakakakilala sa kanya. Kahit sa kanyang mga popular na akda gaya ng Pambungad sa Metapisika (1991), Magpakatao (1979), Pilosopiya ng Relihiyon (1995), at Mga Sinaunang Griyego (1992), bahagyang magbanggit si Ferriols ng tala tungkol sa kanyang sarili. Gaya ng sinomang respetadong pilosoper, tila mas nais niya na gawing bida ang tahi ng mga kaisipang tinatanghal sa kanyang mga aklat sa halip na gawing tampok ng pansin ang kanyang personal na buhay. Dahil dito, maituturing na kakaiba ang aklat na Sulyap Sa Aking Pinanggalingan. Sa obrang ito, mababasa si Ferrriols bilang siya mismong laman ng kwento na siya mismo ang nagsasalaysay. Ang kanyang buhay, ang kanyang mga karanasan, ang kanyang kasaysayan ang tanging paksa na kanyang tinatalakay. Gayunman, hindi simpleng kwento ang binabahagi ni Ferriols, gayundin ang paraan ng paghabi nito. Kaya nga interesante ang gamit ng salitang "sulyap" bilang pamagat. Una, maaari itong ipalagay bilang pagsinop ni Ferriols ng mga retaso ng kanyang nakaraan ngunit sa isang banda, maaari din itong tingnan bilang pagtanaw ng kanyang mga mambabasa sa mga kabanata na kanyang isinasalaysay. May dalawang kilos samakatuwid ang salitang "sulyap" bilang pamagat: sulyap sa panig ni Ferriols na lumilingon sa sariling karanasan at sulyap din sa panig ng mga mambabasa na nabigyan ng pagkakataong masdan si Ferriols sa naratibo ng kanyang nakaraan. Hindi man sinasadya, ang aklat na sa unang tingin ay tila kalipunan lamang ng pira-pirasong gunita, ay naging tila bintana na nagsilbing paraan upang magkatalaban si Ferriols at kanyang mga mambabasa. Isang patunay ang akdang ito sa sinasabi ng pilosoper na

${ }^{1}$ Quezon City: Ateneo de Manila University Press, 2016, 179 pp.

(c) 2017 Jovito V. Cariño

http://www.kritike.org/journal/issue 20/carino2 june2017.pdf

ISSN 1908-7330

$(c c)$ BY-NC-ND 
si Paul Ricoeur na ang naratibo ng buhay ng isang tao ay hindi maihihiwalay sa mas malawak na kwento ng kanyang panahon, gayundin sa kanyang mambabasa. Sa katunayan, mahirap ituring ang Sulyap Sa Aking Pinanggalingan bilang isang autobiograpikong akda. Totoo na ang kwento ay galing sa buhay ni Ferriols subalit malinaw na makikita sa bawat kabanata na hindi ito tungkol lamang sa kanya. Ang salaysay na ibinahagi ni Ferriols ay kasaysayan ng panahon ng ikalawang pandaigdigang digmaan; ng mga paring Heswita, SVD, at Vincentian sa Pilipinas; ng mga sundalong Filipino at Hapon; ng Intramuros, Novaliches, Bataan, at Marikina. Kasaysayan din ito ni Horacio de la Costa, Jaime Bulatao at Teddy Arvisu; ni Mang Kulas, na itinuring ni Ferriols bilang "unang kaibigan namin sa kamatayan;" at ni Manuel de Leon, isang nakakabatang kaibigan ni Ferriols na nasawi sa huling yugto ng pananakop ng mga Hapon sa Pasay. Kwento rin ito ng mga payapang kaparangan ng Pampanga at mga lambak ng Marikina; ng mga wasak na gusali sa Herran at dalamhating bumalot sa mga naninirahan sa Sta. Ana.

Kwento rin ito ng mga mambabasa. Dahil ang libro ay kinatha na parang si Ferriols ay nakikipagkwentuhan lamang, ramdam ng sinomang hahawak dito na bahagi siya sa daloy ng naratibo kahit pa sabihin na ang teksto ay pagbabalik-tanaw sa isang naunang panahon. Sa pagsulyap ni Ferriols sa dati, nagawa niyang isali ang dayuhang mambabasa sa pamamagitan ng pagturing niya sa huli hindi bilang estranghero kundi isang taong nahaharap din sa hamon ng pagsulyap. Dahil dito, nagkaroon ng isang lihim na palitan ng malasakit sa pagitan ng may-akda at sa kanyang mambabasa dahil na rin sa katotohanang ang kwento ng sinoman ay kwentong naiiba pero hind rin lubusang naiiba; iisa tayo ng bigkis sa pagsisikap nating magpakatao. Pinatunayan ni Ferriols na walang iisang larawan na makapaglalahad ng buo kung sino ang sarili at kung ano ang buhay. Kailangang tahiin ito ng pagsulyap sa iba't ibang hibla ng iba't ibang kasaysayan. Isang hamon itong maiiwan sa sinomang lalahok sa sulyap ni Ferriols. 